\title{
Commentaries
}

\section{The father figure in coeliac disease}

\section{The previous story}

It is surprising that although clear reports were given in the pilot work of Ferguson and colleagues, ${ }^{1}$ Farthing and colleagues, ${ }^{2}$ and others about 20 years ago, coeliac disease (CD) has not yet gained popularity among obstetricians. In the subsequent two decades, many epidemiological studies clearly showed that it is a very common disease, that it affects women more than men, and that it has to be considered in relation to reproductive function.

\section{The actual story}

In the past few years several groups have shown that untreated CD is an important cause of abortion, poor outcome of pregnancy, and intrauterine growth retardation. ${ }^{34}$ Most authors agree that malnutrition could not have explained the reproductive difficulties of many, now most, coeliac women. Martinelli and colleagues ${ }^{5}$ recently found that 1 in every 70 pregnant women admitted to a major city hospital suffered from untreated CD: $70 \%$ had a poor outcome of pregnancy, and 8/9 women had a second healthy baby after one year on a gluten free diet.

\section{The issue}

But the paper of Ludvigsson and Ludvigsson in this issue of $G u t^{6}$ raises new questions on a well described story: an unfavourable neonatal outcome was not only associated with maternal $\mathrm{CD}$ but also with paternal $\mathrm{CD}$, which is a new finding (see page 169). Infants of coeliac mothers weighed $222 \mathrm{~g}$ less than the population average, and infants of coeliac fathers weighed $266 \mathrm{~g}$ less than the population average. The risk of a low birth weight baby to coeliac fathers was five times higher than that in the general population $(11 \% v 2.5 \%)$.

\section{The paper}

Ludvigsson and Ludvigsson ${ }^{6}$ report on a large (10 597 births) population based study with the drawback that it was limited to pregnant women who delivered a live baby: the results, although impressive, tend to underestimate the actual prevalence of untreated $\mathrm{CD}$ and the damage induced by undiagnosed disease. There is little doubt that more women who did not become pregnant, had an abortion, or who did not deliver a live baby need to be identified and inclusion of these women would change the results. Similarly, men who could not father a child need to be identified.

The other debatable point is the assumption that mothers with CD were all "treated", which means free from gluten. Unfavourable neonatal outcome would then have not been corrected, or completely corrected, by the gluten free regimen. I agree that awareness of CD is increasing all over Europe and it may be that most diagnosed cases are "treated", but all those involved in the care of CD patients are well aware of the complexity of adhering to a gluten free diet.

The main message of the paper is reinforced by the interesting comparison with diabetes and other autoimmune diseases. It is impressive to see that such symptomatic and severe diseases do not affect pregnancy outcome as much as CD! Diabetic fathers did not generate as many low birth weight babies as coeliac fathers (odds ratio between the two group 13.3). Curiously, the two infants born to both coeliac parents were healthy with a good birth weight: suspicion of a good or very good gluten free kitchen?

Finally, there was a constant significant correlation between the birth weight of infants born to mothers with $\mathrm{CD}$ and that of infants born to fathers with $\mathrm{CD}$, but also with the birth weight of infants who had a sibling or other relative with CD. Thus it appears that there may be "coeliac families".

\section{A special genetic environment?}

Autoimmunity is a reasonable candidate to explain the unfavourable outcome of pregnancy ${ }^{7}$ but it is hard to attribute this hypothesis to coeliac fathers. HLA, as declared by the authors, is unlikely to explain more than a small percentage of this "genetic pattern". CD does not appear to be associated with major genetic defects but it may be caused by a pattern of several genetic "features" in term of genes involved in the immune response as well as those involved in cytokine action and signalling. Coeliac patients are a unique entity, not single individuals, with their own characteristics and features in terms of regulation of cytokines, specificity of immune responses, processing of food antigens, and so on. We still need the artist to paint a clearer portrait of the coeliac patient: many of us scribble on the paper in the attempt.

University of Naples 'Federico II', Italy

L GRECO

1 Ferguson R, Holmes GK, Cooke WT. Coeliac disease, fertility, and pregnancy. Scand $\mathcal{F}$ Gastroenterol 1982;17:65-8.

2 Farthing MJ, Edwards CR, Rees LH, et al. Male gonadal function in coeliac disease: 1. Sexual dysfunction, infertility, and semen quality. Gut 1982;23: 608-14.

3 Ciacci C, Cirillo M, Auriemma G, et al. Coeliac disease and pregnancy outcome. Am $\mathcal{F}$ Gastroenterol 1996;91:718-22.

4 Gasbarrini A, Sanz Torre E, Trivellini C, et al. Recurrent spontaneous aborGasbarrini A, Sanz Torre E, Trivellini C, et al. Recurrent spontaneous abor-
tion and intrauterine fetal growth retardation as symptoms of coeliac tion and intrauterine fetal growth
disease. Lancet 2000;356:399-400.

5 Martinelli P, Troncone R, Paparo F, et al. Coeliac disease and unfavourable outcome of pregnancy. Gut 2000;46:332-5.

6 Ludvigsson JF, Ludvigsson J. Coeliac disease in the father affects the newborn. Gut 2001;49:169-75.

7 Ventura A, Magazzù G, Greco L, et al. Duration of exposure to gluten and risk for autoimmune disorders in patients with coeliac disease. Gastroenterology 1999;117:297-303. 


\section{Signals on the immune tract}

Recent studies have shown that cytokines produced by $\mathrm{T}$ lymphocytes and antigen presenting cells play an important role in both the induction and perpetuation of chronic intestinal inflammation. ${ }^{1-5}$ In particular, the balance between interleukin 12/interferon $\gamma$ and transforming growth factor $\beta$ (TGF- $\beta$ ) responses has been shown to regulate the occurrence of chronic intestinal inflammation. ${ }^{6}$ The TGF- $\beta$ superfamily consists of multifunctional cytokines, including TGF- $\beta$ 1-3, activins, inhibins, and bone morphogenetic proteins. TGF- $\beta 1$ mediates its functions by binding to the accessory TGF- $\beta$ type III receptor that serves as a ligand for the TGF- $\beta$ type II receptor. Receptor bound TGF- $\beta 1$ recruits TGF- $\beta$ type I receptor into the complex leading to formation of a heteromeric complex that finally results in phosphorylation and activation of receptor regulated Smad proteins (Smad2, Smad3). The latter proteins form heteromeric complexes with Smad4 which translocate to the nucleus to control gene transcription hereby mediating the biological effects of TGF- $\beta 1$.

In this issue of Gut, Hahm and colleagues ${ }^{7}$ demonstrate that inactivation of TGF- $\beta$ signalling in the murine intestine by transgenic expression of a dominant negative form of the TGF- $\beta$ type II receptor in the intestinal epithelium (using a ITF/TFF3 promoter construct) results in spontaneous colitis when mice are housed under non specific pathogen free (SPF) conditions (see page 190). Under SPF conditions however transgenic mice did not develop spontaneous colitis but showed enhanced susceptibility to colitis induced by dextran sulphate. These data suggest that TGF- $\beta$ signalling in intestinal epithelial cells plays a crucial role in maintaining mucosal immune homeostasis. Interestingly, colitis development in transgenic animals was associated with increased expression of MHC class II molecules on intestinal epithelial cells and increased activity of matrix metalloproteinases ${ }^{7}$ suggesting that TGF- $\beta$ signalling in intestinal epithelial cells regulates either directly or indirectly antigen presentation and activation of matrix metalloproteinases in the intestine. Understanding the details of the pathogenesis of chronic intestinal inflammation in this novel transgenic model will require further analysis. However, this animal model may be a very useful tool to analyse the functions of TGF- $\beta$ signalling in intestinal epithelial cells at an immunological and molecular level.

The present study extends various previous observations that have suggested an important regulatory role for TGF- $\beta$ in controlling $T$ cell mediated mucosal immune responses. The production of TGF- $\beta$ seems to be a fundamental property of regulatory CD45Rblow $\mathrm{CD}^{+} \mathrm{T}$ cells that can prevent colitis when cotransferred with CD45Rbhigh $T$ cells in SCID mice, ${ }^{8}$ as neutralising antibodies to TGF- $\beta$ can suppress the protective capacities of the former cells in vivo. Furthermore, inactivation of TGF- $\beta 1$ has been shown to result in multiorgan inflammation, including intestinal inflammation that is mediated by activated $\mathrm{T}$ lymphocytes. ${ }^{9-11}$ In addition, disruption of
TGF- $\beta$ signalling in Smad3 knockout mice has been shown to result in intestinal inflammation and colon carcinoma formation. ${ }^{12}{ }^{13}$ Finally, Gorelik and Flavell ${ }^{14}$ recently showed that expression of a dominant negative TGF- $\beta$ receptor type II under a $T$ cell specific promoter results in spontaneous $\mathrm{T}$ cell differentiation and autoimmune disease, suggesting a key role for TGF- $\beta$ signalling in T cell homeostasis. Taken together with the present study, these data suggest that intact TGF- $\beta$ signalling in both intestinal epithelial cells and $\mathrm{T}$ lymphocytes is critical for maintenance of mucosal homeostasis, prevention of proinflammatory cytokine responses and chronic intestinal inflammation. The potential therapeutic relevance of this finding has been suggested by two studies showing that induction of TGF- $\beta$ mediated oral tolerance ${ }^{15}$ and intranasal delivery of a TGF- $\beta 1$ expressing plasmid can suppress chronic intestinal inflammation in mice. ${ }^{16}$ However, as TGF- $\beta$ expression is already increased in patients with inflammatory bowel disease $\mathrm{e}^{17}$ and as TGF- $\beta$ has been implicated in mediating tissue fibrosis and stricture formation in this disease, further studies are necessary before modulation of TGF- $\beta$ responses may be applicable to therapeutic studies in humans.

Thorn Research Building, Brigham and Womens Hospital,

M F NEURATH

Harvard Medical School, Gastroenterology Division,

75 Francis Street, Boston, MA 02115 6195, USA.

neurath@1-med.klinik.uni-mainz.de

1 Podolsky DK. Inflammatory bowel disease. N Engl f Med 1991;325:928-37.

2 Atreya R, Mudter J, Finotto S, et al. Blockade of IL-6 trans-signaling suppresses $T$ cell resistance against apoptosis in chronic intestinal inflammation: Evidence in Crohn's disease and experimental colitis in vivo. Nat Med 2000;6:583-8.

3 Plevy SE, Landers CJ, Prehn J, et al. A role for TNF-alpha and mucosal T helper-1 cytokines in the pathogenesis of Crohn's disease. F Immunol 1997; 159:6276-82.

4 Breese E, Braegger CP, Corrigan CJ, et al. Interleukin-2 and interferongamma secreting $\mathrm{T}$ cells in normal and diseased human intestinal mucosa. Immunology 1993;78:127-31.

5 Monteleone G, Biancone L, Marasco R, et al. Interleukin-12 is expressed and actively released by Crohn's disease intestinal lamina propria mononuclear cells. Gastroenterology 1997;112:1169-78.

6 Strober W, Kelsall B, Fuss I, et al. Reciprocal IFN-gamma and TGF-beta responses regulate the occurrence of mucosal inflammation. Immunol Today responses regul.

$7 \mathrm{Hahm} \mathrm{KB}$, Im YH, Parks TW, et al. Loss of transforming growth factor $\beta$ signalling in the intestine contributes to tissue injury in inflammatory bowel disease. Gut 2001;49:190-8.

8 Powrie F, Carlino J, Leach MW, et al. A critical role for transforming growth factor-beta but not interleukin-4 in the suppression of $T$ helper type 1-mediated colitis by CD45Rb(low) CD4+ T cells. f Exp Med 1996;183:2669-74

9 Kulkarni AB, Huh CG, Becker D, et al. . Transforming growth factor beta1 null mutation in mice causes excessive inflammatory response and early death. Proc Natl Acad Sci USA 1993;90:770-4.

10 Shull MM, Ormsby I, Kier AB, et al. Targeted disruption of the mouse transforming growth factor beta-1 gene results in multifocal inflammatory disease. Nature 1992;359:693-9.

11 Diebold RJ, Eis MJ, Yin M, et al. Early-onset multifocal inflammation in the transforming growth factor beta1-null mouse is lymphocyte mediated. Proc Natl Acad Sci USA 1995;92:12215-19.

12 Yang X, Letterio JJ, Lechleider RJ, et al. Targeted disruption of SMAD3 results in impaired mucosal immunity and diminished $\mathrm{T}$ cell responsiveresults in impaired mucosal immunity and dimir

13 Zhu Y, Richardson JA, Parada LF, et al. Smad3 mutant mice develop metazhu Y, Richardson JA, Parada cancer. Cell 1998;94:703-14.

14 Gorelik L, Flavell RA. Abrogation of TGFbeta signaling in T cells leads to spontaneous $\mathrm{T}$ cell differentiation and autoimmune disease. Immunity 2000;12:171-81.

15 Neurath MF, Fuss I, Kelsall BL, et al. Experimental granulomatous colitis in mice is abrogated by induction of TGF- $\beta$-mediated oral tolerance. $\mathcal{F}$ Exp Med 1996;183:2515-27.

16 Kitani A, Fuss IJ, Nakamura K, et al. Treatment of experimental (TNBS)colitis by intranasal administration of TGF-beta1 plasmid: TGF-beta1mediated suppression of Th1 response occurs by IL-10 induction and IL-12Rb2 chain down-regulation. $\mathcal{F}$ Exp Med 2000;192:41-52.

17 Babyatsky MW, Rossiter G, Podolsky DK. Expression of transforming growth factors alpha and beta in colonic mucosa in inflammatory bowel disease. Gastroenterology 1996;110:975-84. 


\section{Descartes and the gut: "I'm pink therefore I am"}

In 1637 Rene Descartes wrote "The soul by which I am, what I am, is entirely distinct from my body and even if the body were not, the soul would not cease to be what it is". ${ }^{1}$ Descartes was thus reflecting on the longstanding conundrum of relationships between body and soul which have continued to this day and are equally mirrored in our views on diseases of the gastrointestinal tract.

The fathers of gastroenterology clearly recognised the relationships between the brain and gut. In his classic studies of the control of gastric secretion conducted on his subject Tom with a permanent gastric fistula, ${ }^{2}$ Stuart Wolf found that emotional state affected secretion and that mucosal blood flow, measured by a simple thermistor, altered in parallel. ${ }^{3}$ Similar relationships between rectal mucosal blood flow and psychological state were also reported by Almy. ${ }^{4}$ In his now classic "hoax" experiment, he induced anxiety in a "volunteer" by pretending to identify an abnormality during sigmoidoscopy. This induced a marked change in colonic motor activity and a change in mucosal colour.

In the last half century however the onset of an era of objectivity has influenced how we view gastrointestinal symptoms. Quite rightly perhaps, the view that "if you can't measure something you don't know that it exists" has entered gastroenterology. As a result of this scientific rigour, the validity of observations such as those of Wolf and Almy have understandably been questioned. "Where are the controls in a case report?" "What is the repeatability of a hoax?"

A consequence of this objectivity has been that research has become concentrated on that which can be accurately measured and avoidance of that which cannot, irrespective of its relevance to the problems of clinical practice. The pendulum of research endeavour thus swung away from mind-gut interactions over the last half century. Paradoxically however the development of more and more objective technologies for measuring gut function have now begun to return the pendulum to a more balanced position. Thanks to the development of new and powerful brain imaging techniques such as positron emission tomography and functional magnetic resonance imaging, research over the last decade has shown remarkable insights into relationships between the brain and gut. ${ }^{5}$

The recent work by Emmanuel and $\mathrm{Kamm}^{6}{ }^{7}$ represents a further advance in the measurement of brain-gut activity. Using a sensitive laser Doppler flowmeter they measured rectal mucosal blood flow to a high degree of accuracy and showed that it changes in a predictable manner with meal ingestion and in response to pharmacological agents. In their current work $^{89}$ they have re-explored the work of Almy and Wolf and now report the relationships between psychological state and gut mucosal blood flow and the results of behavioural treatment (biofeedback) in patients with constipation (see pages 209 and 214).

What Emmanuel and colleagues ${ }^{8}{ }^{9}$ have found is that rectal mucosal blood flow correlates well with degrees of anxiety/depression expressed in patients with chronic constipation. They have also shown that in patients who respond to behavioural therapy (biofeedback) there is an associated "improvement" in mucosal blood flow. So what does this tell us about Cartesian dualism in functional bowel diseases such as constipation? The results clearly show that it is naïve to continue with the belief that because patients have gut symptoms they must therefore have a gut (and not a brain) disorder. Indeed their studies could be interpreted to indicate that most if not all of the problem in functional gastrointestinal disorders arises from the brain. The real answer is of course not so simple. The reports do not exclude the possibility that a gut located disorder (for example, intrinsic neural damage) could play an important role in the development of constipation. ${ }^{8}{ }^{9}$ However, their interesting findings suggest strongly that whatever the primary cause may be, blood flow changes in constipation are not themselves modulated by the degree of constipation but are related to anxiety levels expressed in patients.

One of the continuing difficulties in studies of the braingut axis in patients with functional gastrointestinal disorders remains the influence of the technique used for studying gut function on the variable being studied and the work of Emmanuel et al, while taking us forwards from the studies of Almy, is still subject to this problem. Measurement of rectal mucosal blood flow by their technique requires rigid sigmoidoscopy for probe placement, and hence those individuals who find rigid sigmoidoscopy a distressing procedure would no doubt show greater alterations in rectal mucosal blood flow during the procedure than those who do not. This is perhaps one explanation for the stronger relationship between anxiety state and rectal mucosal blood flow in constipated patients. The fundamental question of whether constipation is a gut manifestation of an altered psychological state or a psychological manifestation of altered gastrointestinal state therefore unfortunately remains unanswered.

Do the studies of Emmanuel et al on biofeedback help us unravel this problem? The paper ${ }^{9}$ shows that effective behavioural therapy (biofeedback) improves both symptoms and rectal blood flow in $60 \%$ of constipated patients. Does this therefore indicate that colonic function is improved by biofeedback? While it is reassuring to note that patients feel better, constipation itself seemed to be more difficult to move, and marker transit showed only a small improvement. Here again the relationship between the measured variable and its effect on the measurement becomes relevant. In the study of Emmanuel and Kamm, improvement in rectal mucosal blood flow could only be noted at the time of sigmoidoscopy, which perhaps could simply indicate that biofeedback increased patient tolerance to sigmoidoscopy!

While the studies of Emmanuel et al on CNS control of mucosal blood flow ${ }^{89}$ are a valuable advance and place our understanding of mind-body relationships on a yet more objective footing, they inevitably raise as many questions as they answer, and the problem of Descartian dichotomy is not yet completely resolved for functional disorders. If the gut had its own mind and could express its views about the conundrum, perhaps it might paraphrase Descartes' famous maxim and respond in the following manner: "I'm pink, therefore I am".

D G THOMPSON

Section of GI Sciences, University of Manchester,

Hope Hospital, Salford M6 8HD, UK

dthompso@fs1.ho.man.ac.uk

\footnotetext{
1 Holdane ES, Ross GRT, eds. The philosophical works of Descartes. New York: Cambridge University Press, 1970.

2 Wolf S. The stomach. New York: Oxford University Press, 1965.
} 
3 Richards $\mathrm{CH}$, Wolf S, Wolff HG. The measurement and recording of gastroduodenal blood flow in man by means of a thermal gradientometer. f Clin Invest 1942:21:551.

4 Almy TP. Experimental studies on the irritable colon. $\mathrm{Am}$ f $\mathrm{Med}$ 1951;10:60.

5 Aziz Q, Thompson DG. Brain-gut axis in health and disease. Gastroenterology 1998;114:559-78.

6 Emmanuel AV, Kamm MA. Laser Doppler measurement of rectal mucosal blood flow. Gut 1999;45:64-9.
7 Emmanuel AV, Kamm MA. Laser Doppler flowmetry as a measure of Emmanuel AV, Kamm MA. Laser Doppler flowmetry as a measure of extrinsic

8 Emmanuel

Emmanuel AV, Mason HJ, Kamm MA. Relationship between psychological state and level of activity of extrinsic gut innervation in patients with a functional gut disorder. Gut 2001;49:209-13.

9 Emmanuel AV, Kamm MA. Response to a behavioural treatment, biofeedback, in constipated patients is associated with improved gut transit and autonomic innervation. Gut 2001;49:214-19.

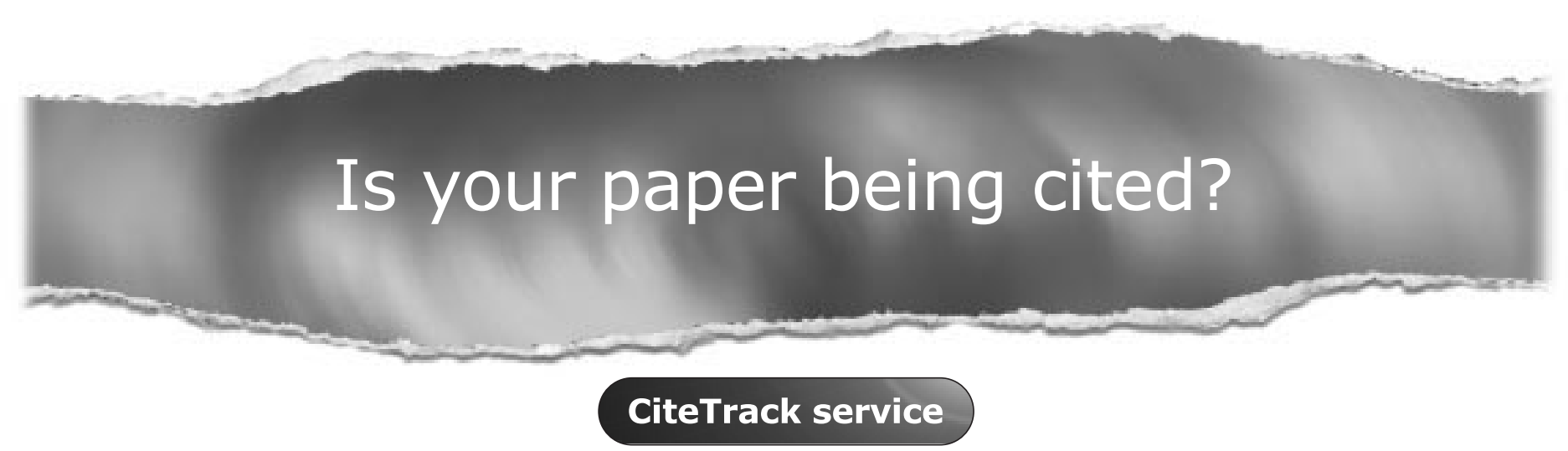

CiteTrack will alert you by email whenever new content in Gut or a participating journal is published that matches criteria you want to track

Topics: Tell CiteTrack which words or subjects to watch for in new content Authors: Be alerted whenever key authors you are following publish a new paper Articles: Know whenever a paper of interest to you is referenced by another paper

\section{www.gutjnl.com}

